\title{
Control of Coupled Tank Liquid Level System Using Sliding Mode Control
}

\author{
${ }^{* 1}$ B.Amarendra Reddy, ${ }^{2}$ G. Ananda Rao, ${ }^{3}$ K. Anusha, ${ }^{4}$ B. Pavan Kumar \\ 1,2,3,4 Department of Electrical Engineering,Andhra University(A) \\ Email: bamarendrareddy@yahoo.com
}

\section{Received: 10 $^{\text {th }}$ December 2017, Accepted: 17th January 2018, Published: 28th February 2018}

\begin{abstract}
Designing a controller for coupled tank liquid level system under tracking conditions is a challenging task. First order sliding mode controller is designed and implemented for liquid level coupled tank system under distinct tracking signals. The proposed controller was designed by using tracking error approach. The designed non-linear controller is capable of tracking the desired water level for all set points with high degree of accuracy, with less rise time and with less significant overshoot. The controller shows robustness against the disturbance in the plant and produced an appropriate control signals for the motive of controlling the liquid level in the coupled-tank system. A simulation is carried out using MATLAB to control this system for different tracking signals.
\end{abstract}

Keywords: Modeling, Coupled-tank, Sliding Mode Control.

\section{Introduction}

The control of a liquid level in tanks is a basic problem in process industries, where often it is required to store some amount of liquid in tanks and after that transferred to other one[1]. For regulating liquid level in coupled tank system requires an efficient and robust controller. One particular approach to robust controller design is so called sliding mode control (SMC) methodology. This type of liquid level systems are used in various industries like steel industries, thermal plants, food processing industries, chemical industries, etc.

In this paper a robust control strategy to control the liquid level of $2^{\text {nd }}$ tank in coupled tank system was designed. This can be achieved by using Sliding Mode Control (SMC) which is belong to the Variable Structure Control Systems (VSCS). Variable Structure Control System (VSCS) is a grade of systems whereby the control law changes during the control process according to some defined produce which depends on the state of the system [4]. The most distinguished feature of VSC is its ability towards robust control systems and using VSC in many cases results invariant control systems. The term "invariant" means that the system is completely insensitive to parametric uncertainty and external disturbances.[5]
This paper is organized as follows. System description of a coupled tank is discussed in section II. Mathematical modeling of the coupled tank system is discussed in the section III. Sliding Mode aspects and Control strategy derivation for generalized system is discussed in section IV. SMC design for a coupled tank system is discussed in Section V. Simulation results are discussed in section VI. Conclusion presented in section VII.

\section{System Description}

The coupled tank consists of two tanks coupled using a pipe. ' $\mathrm{A}_{1}$ ' and ' $\mathrm{A}_{2}$ ' are the cross section areas of the tank 1 and tank 2 respectively. ' $q$ ' is the flow rate of the liquid for the tank 1 . ' $\mathrm{q}_{1}$ ' is the flow rate between tank 1 and tank 2 . Finally, $\mathrm{q}_{2}$ is the out flow rate of the liquid from tank 2 . ' $\mathrm{H}_{1}$ ' and ' $\mathrm{H}_{2}$ ' are the heights of the liquid level in tank 1 and tank 2 respectively. The Parameters $\mathrm{B}_{1}, \mathrm{~B}_{2}$ and $\mathrm{B}_{12}$ appears in modeling equations, are the proportionality constants. These are depends on the coefficients of discharge, gravitational constant and the crosssectional area of each outlet.

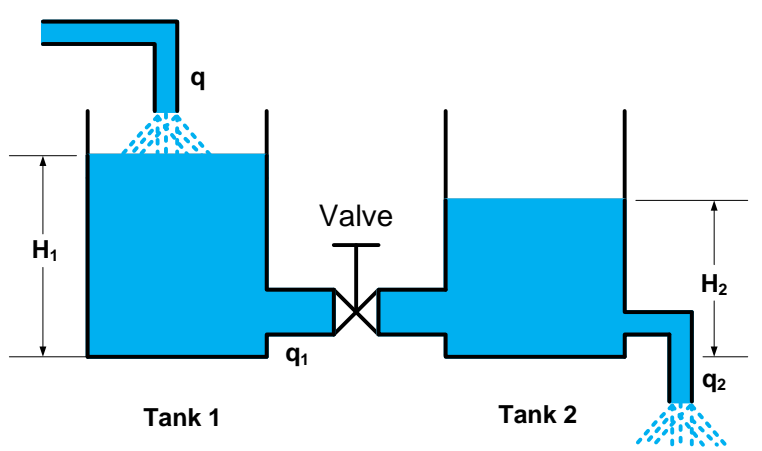

Fig 1. Representing a coupled tank system

\section{Mathematical Modeling}

Fig 1 shows the physical representation of a coupled tank system. Pump supplies water to the tank 1. Tank 1 and Tank 2 were connected using a small pipe with the help of a valve. And there is an outlet connected to tank 2. The liquid used in the plant is assumed to be steady, non-viscous and incompressible. The non-linear state equations of the coupled tank are obtained using Bernoulli's equation.

The differential equations of tank 1 and tank 2 are obtained using the flow balance equation and given in equation (1). 


$$
\begin{aligned}
& \frac{\mathrm{dH}_{1}}{\mathrm{dt}}=\frac{1}{\mathrm{~A}_{1}}\left(\mathrm{q}-\mathrm{q}_{1}\right) \\
& \frac{\mathrm{dH}}{\mathrm{dt}}=\frac{1}{\mathrm{~A} 2}\left(\mathrm{q}_{1}-\mathrm{q}_{2}\right)
\end{aligned}
$$

Where $\mathrm{q}_{1}$ and $\mathrm{q}_{2}$ are defined [2] given as below.

$$
\begin{gathered}
\mathrm{q}_{1}=\mathrm{a}_{12} \sqrt{2 \mathrm{~g}\left(\mathrm{H}_{1}-\mathrm{H}_{2}\right)} \text { if } \mathrm{H}_{1}>\mathrm{H}_{2} \\
\mathrm{q}_{2}=\mathrm{a}_{2} \sqrt{2 \mathrm{gH}_{2}} \text { if } \mathrm{H}_{2}>0
\end{gathered}
$$

And $\mathrm{a}_{12}$ and $\mathrm{a}_{2}$ are the cross section area of pipes connecting the two tanks and outlet respectively. On substitution of the $\mathrm{q}_{1}$ and $\mathrm{q}_{2}$, the differential equations of the coupled tank system are obtained and given in equation (2).

$$
\begin{aligned}
& A_{1} \frac{d H_{1}}{d t}=q-B_{12} \sqrt{\left|H_{1}-H_{2}\right|} \operatorname{sign}\left(H_{1}-H_{2}\right) \\
& A_{2} \frac{d H_{2}}{d t}=-B_{2} \sqrt{H_{2}}+B_{12} \sqrt{\left|H_{1}-H_{2}\right|} \operatorname{sign}\left(H_{1}-H_{2}\right)
\end{aligned}
$$

Since there is no leakage provided in tank 1 , assume $\mathrm{B}_{1}=0$. Here $\mathrm{B}_{2}$ is output discharge proportionality constant and mathematically defined using equation (3). And $B_{12}$ is discharge proportionality constant between the tank 1 and tank 2 .

$$
\begin{aligned}
& \mathrm{B}_{2}=\mathrm{a}_{2} \sqrt{2 \mathrm{~g}} \\
& \mathrm{~B}_{12}=\mathrm{a}_{12} \sqrt{2 \mathrm{~g}}
\end{aligned}
$$

This system can be modeled in terms of non linear functions $\mathrm{f}$ and $\mathrm{b}$ i...e, $\mathrm{f}$ is a nonlinear function involving $\mathrm{H}_{1}$ and $\mathrm{H}_{2}$ variables (square root of $\mathrm{H}_{1}$ and $\mathrm{H}_{2}$ ).

$$
\dot{H}(t)=f(H)+b(H) u
$$

\section{Sliding Mode Controller Design}

Sliding mode control is an approach to controller design that explicitly deals with uncertainty for incompletely modeled or non linear system. One of the most important features of SMC is that it utilizes a discontinuous control action, which switches between two distinctively different control structures such that a new type of system motion called sliding mode exists in a specified manifold [5]. The Sliding Mode Control (SMC) design consists of two basic steps (i) defining a sliding surface along which the system can slide to its desired final states. The system trajectories are constrained onto a surface in the state space called the sliding surface. (ii) Designing a control law. The function of the control law is to attract the system trajectories towards sliding surface in finite time and also to keep the trajectories on the sliding surface. The control law consists of linear and nonlinear parts.

\section{(i) System Description:}

The non-linear system dynamics can be described using the state equation (5).

$$
\begin{aligned}
& \dot{\mathrm{x}}_{1}=\mathrm{f}\left(\mathrm{t}, \mathrm{x}_{1}, \mathrm{x}_{2}, \ldots \ldots \ldots \ldots \mathrm{x}_{\mathrm{n}}, \mathrm{u}_{1}, \mathrm{u}_{2}, \ldots \ldots . \mathrm{u}_{\mathrm{p}}\right) \\
& \dot{\mathrm{x}}_{2}=\mathrm{f}\left(\mathrm{t}, \mathrm{x}_{1}, \mathrm{x}_{2}, \ldots \ldots \ldots \ldots \mathrm{x}_{\mathrm{n}}, \mathrm{u}_{1}, \mathrm{u}_{2}, \ldots \ldots \ldots \mathrm{u}_{\mathrm{p}}\right) \\
& \dot{\mathrm{x}}_{3}=\mathrm{f}\left(\mathrm{t}, \mathrm{x}_{1}, \mathrm{x}_{2}, \ldots \ldots \ldots \ldots \mathrm{x}_{\mathrm{n}}, \mathrm{u}_{1}, \mathrm{u}_{2}, \ldots \ldots \ldots \mathrm{u}_{\mathrm{p}}\right) \\
& \cdot \cdot \\
& \cdot \cdot \\
& \dot{\mathrm{x}}_{\mathrm{n}}=\mathrm{f}\left(\mathrm{t}, \mathrm{x}_{1}, \mathrm{x}_{2}, \ldots \ldots \ldots \ldots \mathrm{x}_{\mathrm{n}}, \mathrm{u}_{1}, \mathrm{u}_{2}, \ldots \ldots \ldots \mathrm{u}_{\mathrm{p}}\right)
\end{aligned}
$$

Where $\mathrm{x}_{1}, \mathrm{x}_{2}, \mathrm{x}_{3}, \ldots \ldots \ldots \ldots . . . \mathrm{x}_{\mathrm{n}}$ are state variables, $\mathrm{u}_{1}, \mathrm{u}_{2}, \mathrm{u}_{3}, \ldots \ldots \ldots \ldots \mathrm{u}_{\mathrm{n}}$ are specified input variables, and $\dot{\mathrm{x}}_{1}, \dot{\mathrm{x}}_{2}, \dot{\mathrm{x}}_{3}, \ldots \ldots \ldots \ldots \ldots \ldots \ldots . . . . . \dot{\mathrm{x}}_{\mathrm{n}}$ are derivatives of the state variables.

(ii) Switching function Description:

A linear sliding surface can be defined using the equation (6).

$$
\mathrm{s}=\mathrm{e}^{(\mathrm{n}-1)}+\ldots \ldots \ldots \ldots \ldots \ldots+\mathrm{c}_{2} \ddot{\mathrm{e}}+\mathrm{c}_{1} \dot{\mathrm{e}}+\mathrm{c}_{0} \mathrm{e}
$$

Where $\mathrm{e}=\mathrm{x}-\mathrm{x}_{\mathrm{d}}$ and $\mathrm{c}_{\mathrm{i}}$ is the coefficients selected such that the polynomial

$$
\lambda^{\mathrm{n}-1}+\sum_{\mathrm{i}=0}^{\mathrm{n}-2} \mathrm{c}_{\mathrm{i}} \lambda^{\mathrm{i}}=0
$$

is Hurwitz polynomial. If the sliding surface ' $\mathrm{s}$ ', is made to zero then the tracking error will automatically converges to zero asymptotically by virtue of polynomial being Hurwitz [1].

\section{(iii) Control law construction:}

The control law of the FOSMC is expressed as follows:

$$
\mathrm{u}=\mathrm{u}_{\mathrm{eq}}+\mathrm{u}_{\mathrm{d}}
$$

with $u_{e q}$ is the equivalent control and $u_{d}$ is the discontinuous control. The discontinuous control signal is selected so as to bring the state trajectories towards the switching surface or sliding surface [4]. The equivalent control is a control action necessary to maintain an ideal sliding motion in other words it ensures the state trajectory to remain on the switching surface $\mathrm{s}=0$ during the sliding mode.

The equivalent control $u_{e q}$ is obtained by setting $\left.\dot{\mathrm{s}}(\mathrm{x}, \mathrm{u}, \mathrm{t})\right|_{\mathrm{u}=\mathrm{u}_{\mathrm{eq}}}=0$ where $\dot{\mathrm{s}}=\mathrm{f}(\mathrm{x}, \mathrm{u}, \mathrm{t})$. The discontinuous control can be defined as

$$
\mathrm{u}_{\mathrm{disc}}=\operatorname{ksign}(\mathrm{s}) \quad \text { Or } \mathrm{k} \frac{\mathrm{s}}{|\mathrm{s}|+\delta}
$$

\section{SMC for Coupled Tank System}

For coupled tank system to regulate the tank 2 liquid level $\mathrm{H}_{2}$ to a desired value $\mathrm{H}_{\mathrm{d}}$, the sliding surface ' $\mathrm{s}$ ' is defined as

$$
\mathrm{s}=\dot{\mathrm{e}}+\lambda \mathrm{e}
$$

Where $\mathrm{e}=\mathrm{H}_{2}-\mathrm{H}_{\mathrm{d}}, \dot{\mathrm{e}}=\dot{\mathrm{H}}_{2}, \ddot{\mathrm{e}}=\ddot{\mathrm{H}}_{2}$ 
By differentiating ' $s$ ' with respect to time

$$
\dot{\mathrm{s}}=\ddot{\mathrm{e}}+\lambda \dot{\mathrm{e}}
$$

Here

$$
\mathrm{s}=\dot{\mathrm{H}}_{2}+\lambda\left(\mathrm{H}_{2}-\mathrm{H}_{\mathrm{d}}\right)
$$

$\ddot{\mathrm{H}}_{2}$ can be represented as

$$
\ddot{\mathrm{H}}_{2}=\mathrm{f}(\mathrm{H})+\mathrm{b}(\mathrm{H}) \mathrm{u}
$$

By substituting (13) in (11) we get

$$
\dot{\mathrm{s}}=\mathrm{f}(\mathrm{H})+\mathrm{b}(\mathrm{H}) \mathrm{u}+\lambda \dot{\mathrm{H}}_{2}
$$

The SMC law can be expressed as follows

$$
\mathrm{U}=\mathrm{u}+\mathrm{u}_{\text {disc }}
$$

The linear component of ' $u$ ' is obtained by making, $\dot{\mathrm{s}}=0$

$$
\mathrm{u}_{1}=\frac{1}{\mathrm{~b}(\mathrm{H})}\left[-\mathrm{f}(\mathrm{H})-\lambda \dot{\mathrm{H}}_{2}\right]
$$

The nonlinear component of the SMC is considered as

$$
\begin{gathered}
\mathrm{u}_{\text {disc }}=\mathrm{k} \frac{\mathrm{s}}{|\mathrm{s}|+\delta} \\
\mathrm{U}=\frac{1}{\mathrm{~b}(\mathrm{H})}\left[-\mathrm{f}(\mathrm{H})-\lambda \dot{\mathrm{H}}_{2}\right]+\mathrm{k} \frac{\mathrm{s}}{|\mathrm{s}|+\delta}
\end{gathered}
$$

\section{Results and Discussion}

By using the SM controller a liquid level in tank 2 is regulated with a desired constant level is at $10 \mathrm{~cm}$. To achieve this liquid level the SM controller is made to regulate the flow rate ' $\mathrm{q}$ ' at the tank 1 , so that, desired level of tank 2 is achieved. The saturation function used in the simulation to achieve the control signal remains always within the limits. The values of tuning parameters are considered as $\mathrm{k}=358$ and $\delta=0.21$. The tracking performance of this system with this control strategy is tested for various command signals step, saw tooth, square, sine, and random signals.

For this coupled tank with the parameters listed in table I simulations are carried out. The regulation

\begin{tabular}{|c|c|c|c|c|}
\hline & Symbol & \multicolumn{3}{|c|}{$\begin{array}{l}\text { Parametric } \\
\text { Values }\end{array}$} \\
\hline $\begin{array}{l}\text { Cross sectional area of each } \\
\text { tank }\end{array}$ & $\begin{array}{c}A_{1} \text { and } A_{2} \\
\mathrm{~cm}^{2}\end{array}$ & \multicolumn{3}{|c|}{35} \\
\hline $\begin{array}{l}\text { Proportionality } \\
\text { constant which }\end{array}$ & \multirow[t]{3}{*}{$\mathrm{B}_{\mathrm{i}}$} & $\mathrm{B}_{1}$ & $\mathrm{~B}_{2}$ & $\mathrm{~B}_{12}$ \\
\hline $\begin{array}{l}\text { depends upon the cross } \\
\text { sectional area }\end{array}$ & & 15 & 15 & 25 \\
\hline $\begin{array}{c}\text { of tank and } \\
\text { gravitational constant }\end{array}$ & & & & \\
\hline Gravitational constant & $\begin{array}{c}\mathrm{g} \\
\mathrm{cm} / \mathrm{sec}^{2}\end{array}$ & \multicolumn{3}{|c|}{981} \\
\hline Constant & $\lambda$ & \multicolumn{3}{|c|}{1.5} \\
\hline Tuning parameter & $\mathrm{k}$ & \multicolumn{3}{|c|}{358} \\
\hline Tuning parameter & $\delta$ & \multicolumn{3}{|c|}{0.21} \\
\hline
\end{tabular}
of liquid level is plotted for various initial conditions when the required step reference is set to be $10 \mathrm{cms}$ and shown in Fig. (2(a)). The error and the corresponding control signals are plotted and shown in figures Fig. (2(b)) and Fig. (2(c)).
Table I Parameters of the Liquid Level Coupled Tank

Simulation results that were obtained using MATLAB were obtained as follows

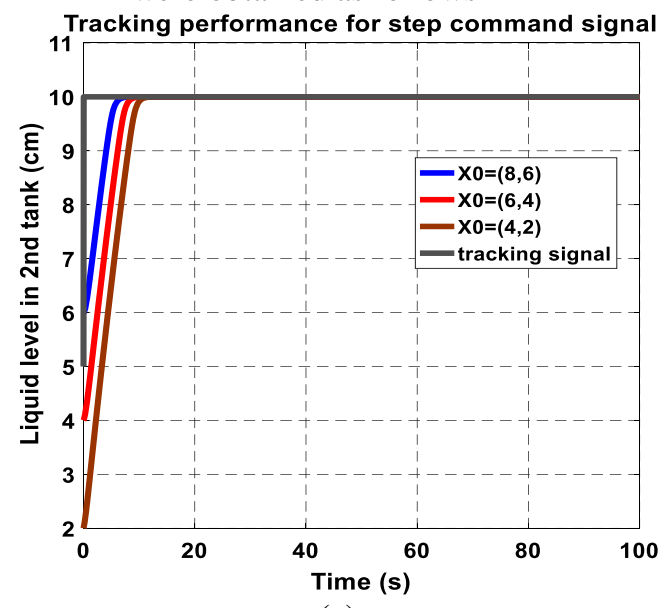

(a) 


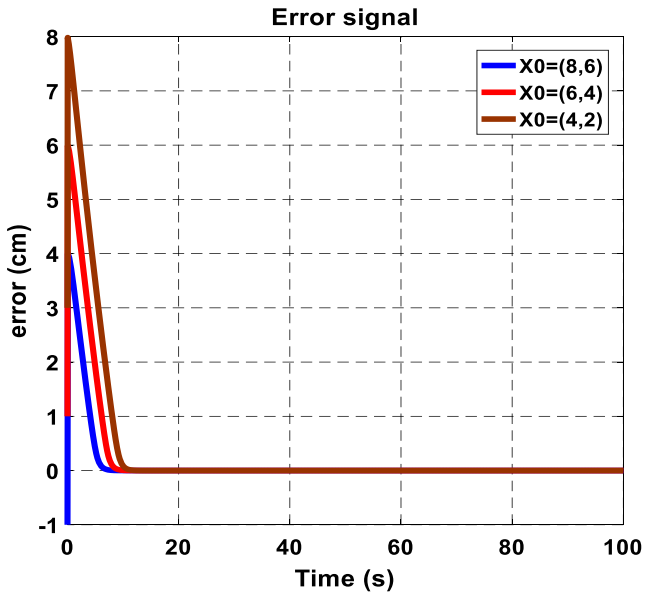

(b)

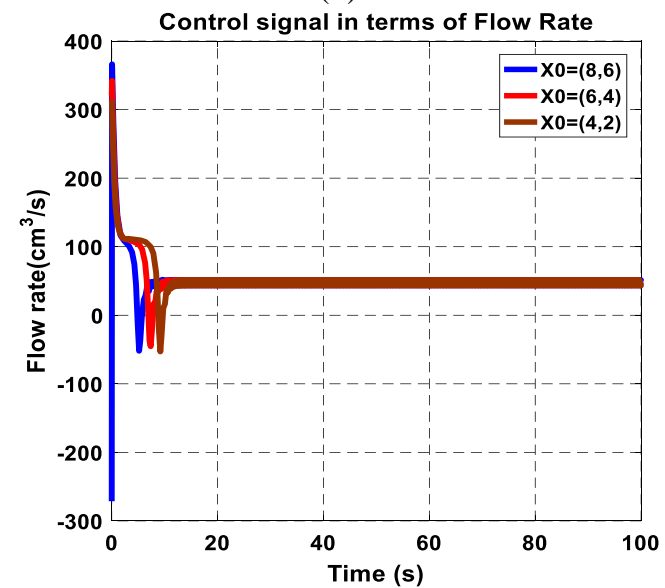

(c)

Fig .2. (a) Tracking performance (b) error signal (c) control signal under step reference

The tracking performance of liquid level tank system with SM control strategy is tested for sinusoidal reference with various initial conditions and shown in Fig. (3(a)). The error and the corresponding control signals are plotted and shown in figures Fig.(3(b)) and Fig.(3(c)).

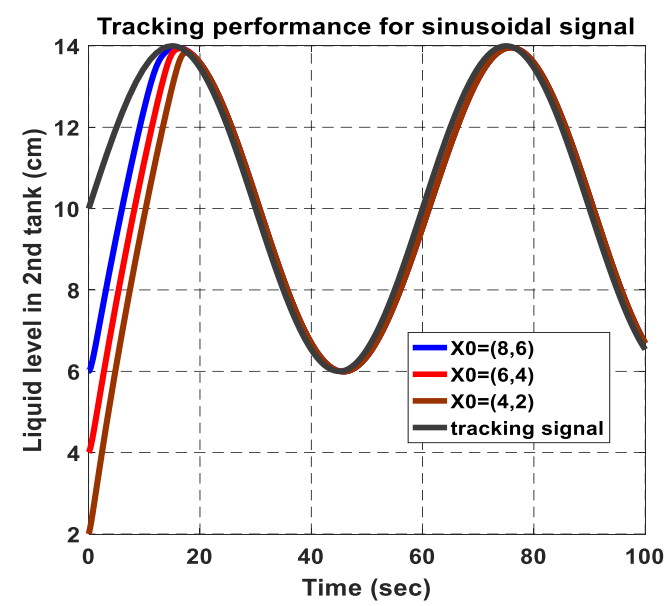

(a)

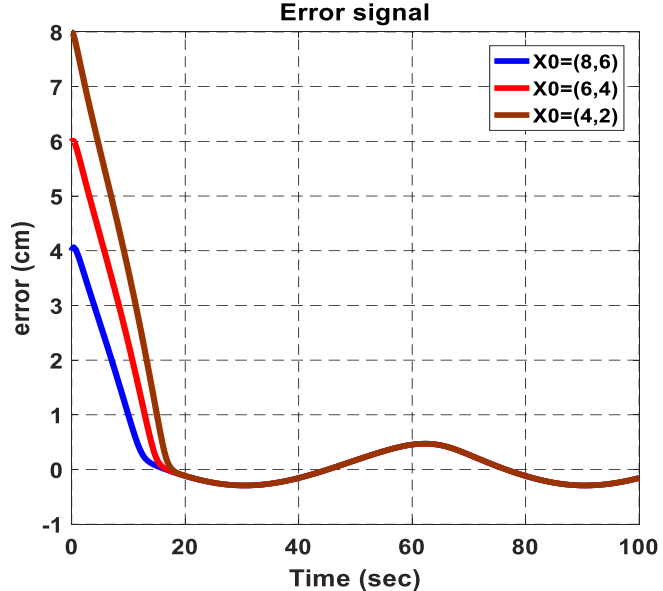

(b)

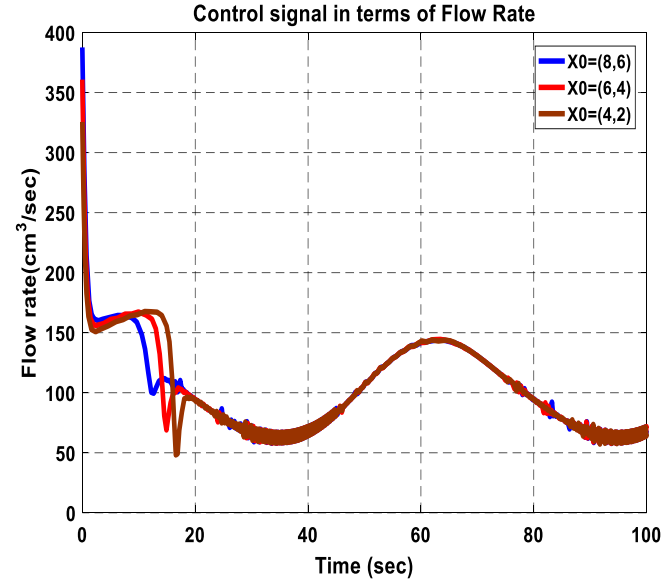

(c)

Fig .3. (a) Tracking performance (b) error signal (c) control signal under sine wave reference

The tracking performance of liquid level tank system with SM control strategy is tested for sawtooth reference with various initial conditions and shown in Fig. (4(a)). The error and the corresponding control signals are plotted and shown in figures Fig. (4(b)) and Fig.(4(c)).

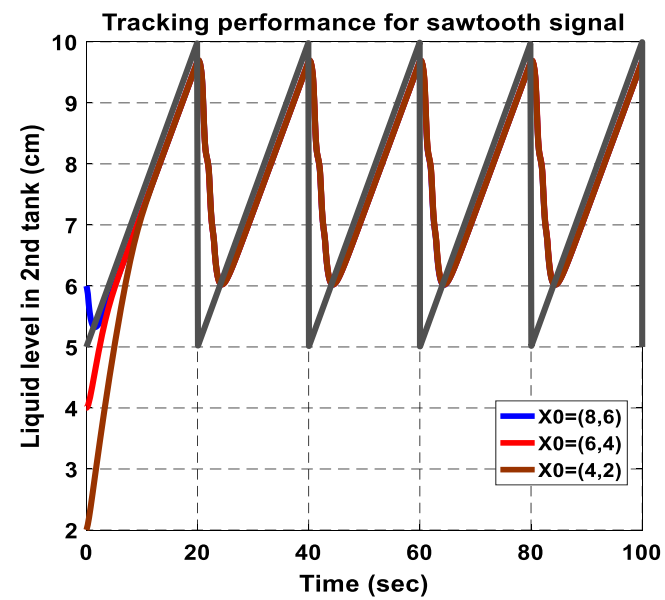

(a) 


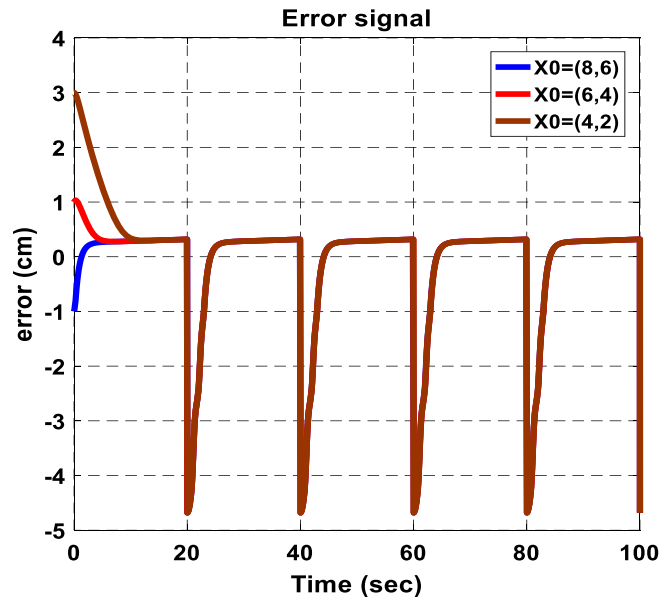

(b)

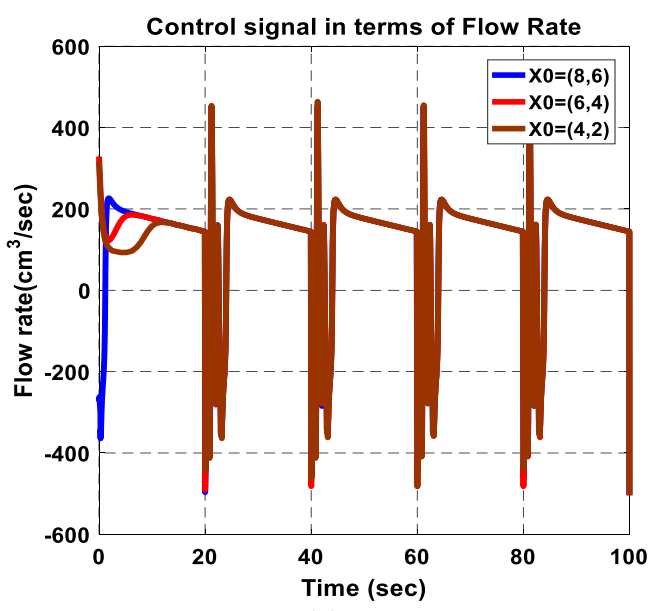

(c)

Fig .4. (a) Tracking performance (b) error signal (c) control signal under sawtooth wave reference

The tracking performance of liquid level tank system with SM control strategy is tested for random reference with various initial conditions and shown in Fig. (5(a)). The error and the corresponding control signals are plotted and shown in figures Fig. (5(b)) and Fig. (5(c)).

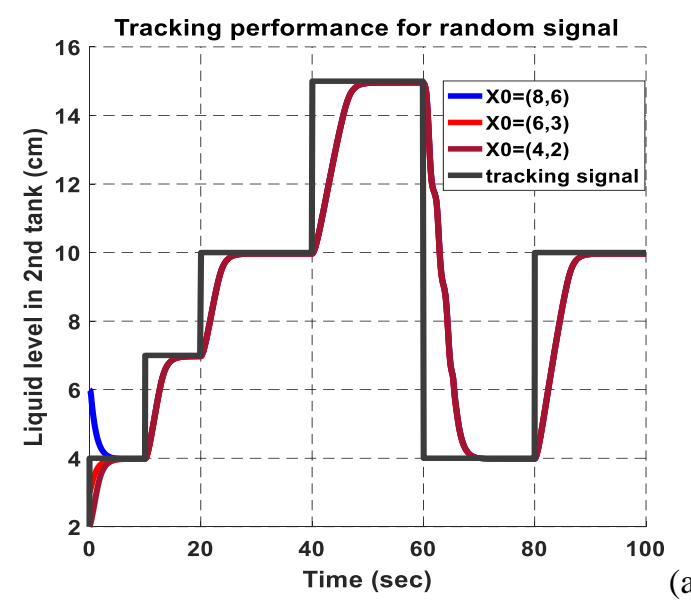

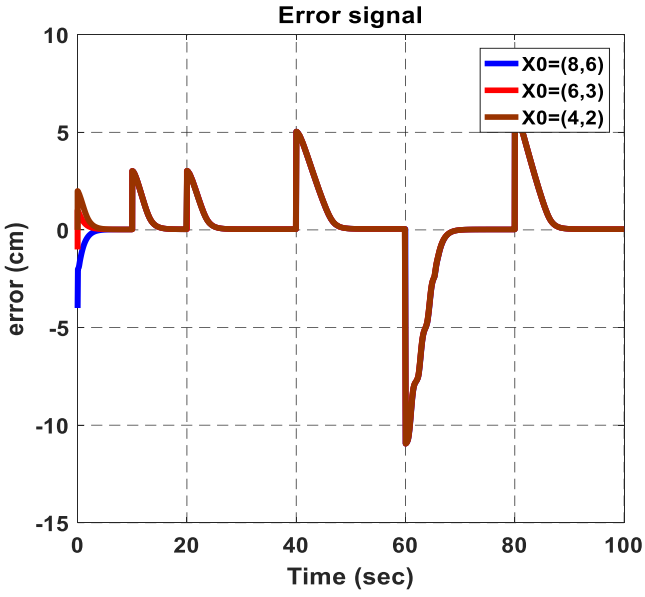

(b)

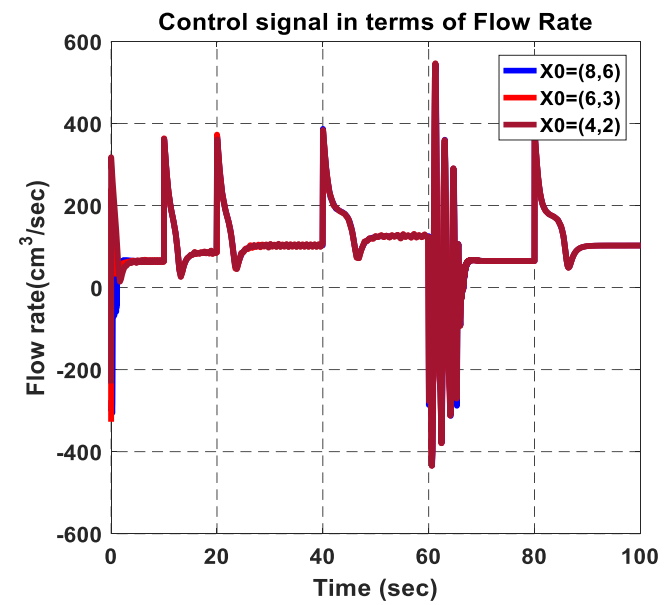

(c)

Fig .5. (a) Tracking performance (b) error signal (c) control signal under random wave reference

The tracking performance of liquid level tank system with SM control strategy is tested for square reference with various initial conditions and shown in Fig. (6(a)). The error and the corresponding control signals are plotted and shown in figures Fig. (6(b)) and Fig.(6(c)).

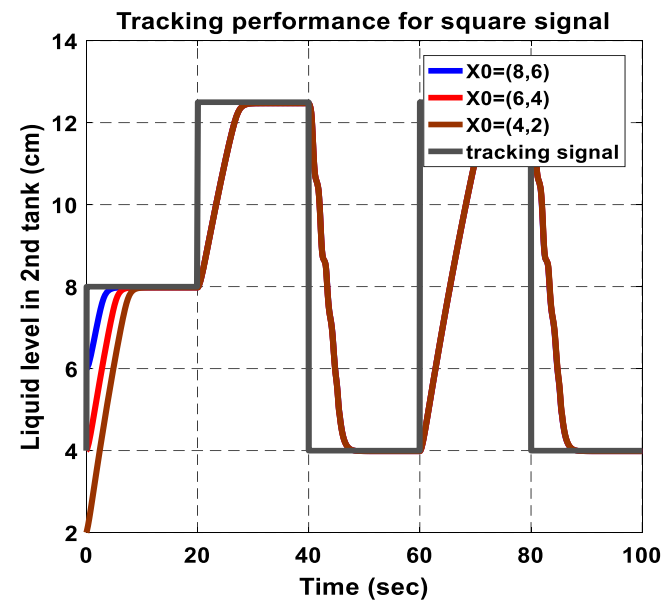

(a) 


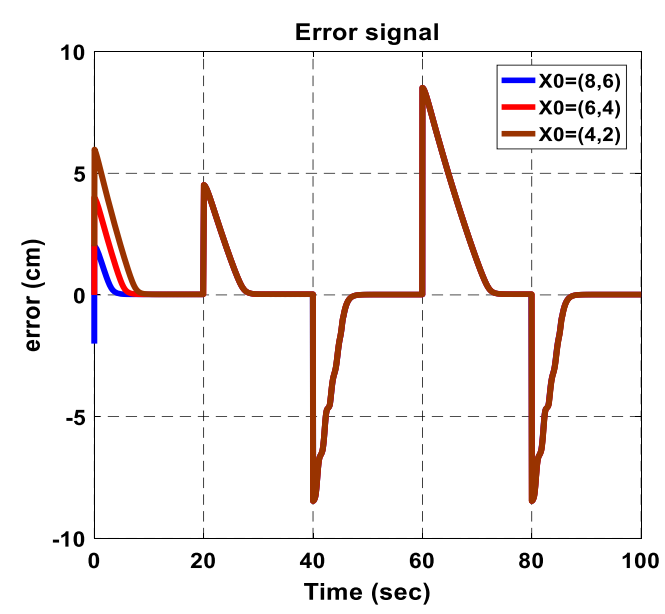

(b)

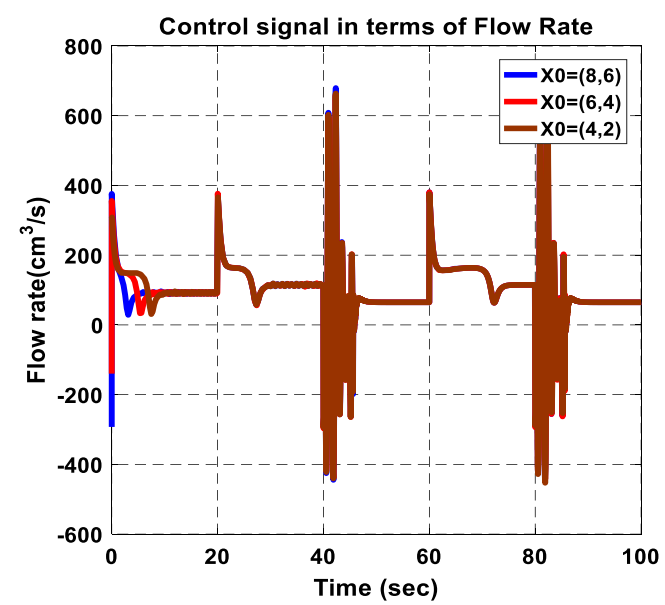

(c)

Fig .6. (a) Tracking performance (b) error signal (c) control signal under square wave reference

When the liquid level tank system is subjected to a step disturbance of magnitude 0.2 and the corresponding regulation and the control and error signals are plotted and shown in Fig. (7(b)) and Fig. (7) $)$.

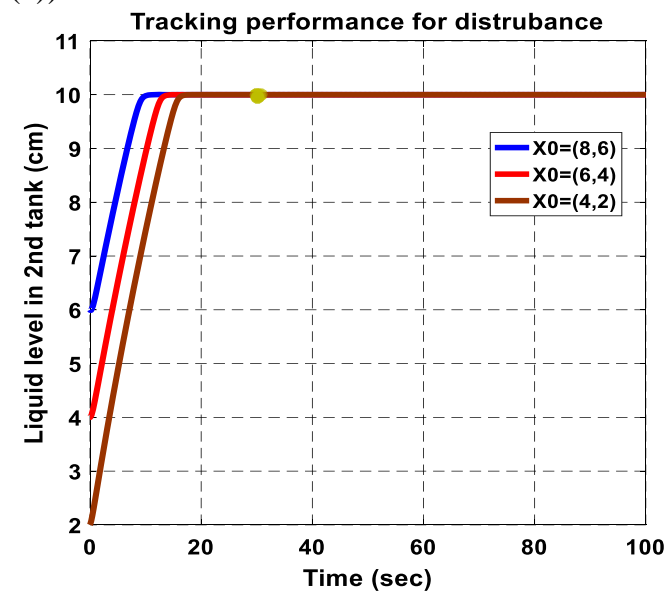

(a)

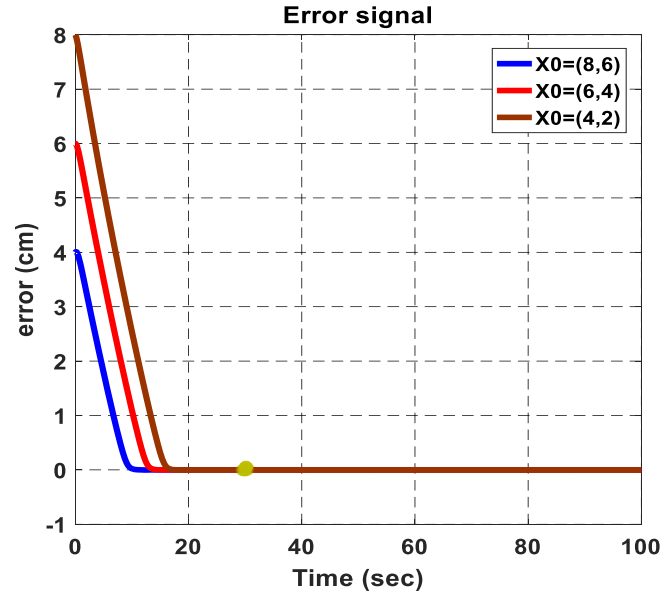

(b)

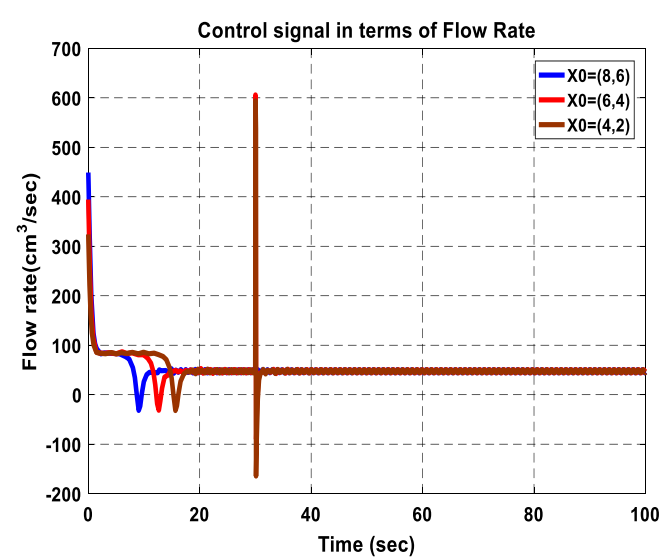

(c)

Fig.7. (a) Tracking performance (b) error signal (c) control signal under the influence of disturbances

\section{Conclusions}

First order sliding mode control was designed successfully under various initial conditions of a non linear coupled tank liquid level system. The switching surface and sliding mode control law was designed for tracking various input signals like step, square wave, saw tooth, sinusoidal, and random signals and also under disturbance conditions. The tracking performance, error signal and control signals are plotted in time domain in the MATLAB environment.

\section{References}

1. Hur Abbas, Sajjad Asghar, Shahid Qamar, "Sliding Mode Control For Coupled-Tank Liquid Level Control System", 2012 10th International Conference on Frontiers of Information Technology.

2. Fayiz Abu Khadra and Jaber Abu Qudeiri, "Second Order Sliding Mode Control of the Coupled Tanks System", Hindawi publishing Corporation Mathematical Problems in Engineering Volume 2015.

3. Hayriye Tugba, Kaan, Abdullah, "RealTime Application of Sliding Mode Controller for Coupled Tank Liquid Level 
System", International Journal of Applied Mathematics, Electronics and Computers.

4. Christopher Edwards and Sarah K. Spurgeon "Sliding mode control: theory and applications".

5. Ligang $\mathrm{Wu}$, Peng shi and Xiaojie Su "sliding mode control of uncertain parameter-switching hybrid systems". 